\title{
Bireysel Yenilikçilik Sınıflandırması ve Öz Yeterlilik İlişkisi: Mutfak Çalışanlarında Bir Araştırma ${ }^{1}$
}

\author{
DOI: 10.26466/opus.816491
}

\begin{abstract}
*
Ediz Güripek ${ }^{*}$ - Cemal İnce ${ }^{* *}$ - Serdar Eren ***

* Dr. Öğr. Üyesi, Tokat Gaziosmanpaşa Üni. Zile Dinçerler Turizm İşletmeciliği ve Otelcilik Y.O E-Posta: edizguripek@yahoo.com

ORCID: 0000-0001-9573-2674

** Dr. Öğr. Üyesi, Tokat Gaziosmanpaşa Üni. Zile Dinçerler Turizm İşletmeciliği ve Otelcilik Y.O E-Posta: cemal.ince@gop.edu.tr ORCID: 0000-0003-2005-7090

*** Dr. Öğretim Üyesi, Kütahya Dumlupınar Üniversitesi, Tavşanlı Uygulamalı Bilimler Fakültesi

E-Posta: serdar.eren@dpu.edu.tr ORCID: 0000-0001-9733-2308

\section{Öz}

Kişisel doyumu gerçekleştirmiş müşterilerin odağında yiyecek-içecek işletmelerinden hedonik duyguları tatmin etmek, sunduğu yiyecek ve içeceklerden çok daha önemli hale gelmiştir. Bu nedenle yiyecek içecek işletmelerinde müşteri memnuniyetinin sağlanmasında sadece ürünler değil yenilikçi düşünce ve uygulamalar da büyük önem kazanmıştır. Rekabet avantajı elde etmek isteyen işletmelerin yenilikçi stratejiler geliştirmeleri kaçınılmazdır.Yenilik yapabilmek için bireysel olarak yenilik yeteneğine sahip olmak gereklidir. Çünkü yenilik yapma yeteneğine sahip çalışanlar, yenilikçi olmayan çalışanlara göre daha orijinal düşüncelere sahip, cesur, girişimci ve bağımsız kişilerdir. Yenilikçi kişiliğin, yeni ürünlerin arz edilmesi, yeni üretim tekniklerinden yararlanma, yeni müşteri ve pazarlarn elde edilmesi, yeni hizmet yöntemlerinin bulunması gibi çeşitli konularda işletmeye yararlar sağlayabileceğgi bir gerçektir. Yenilikçi kişiliğe sahip olan çalışanlarda bulunan bir diğer özellik ise öz yeterliliktir. Öz yeterlilik; çalışanın ilgili alanda kendisinden beklenen davranışları gerçekleştirmek için sahip olduğu bilgi ve yeteneklerinin farkında olması ile bunları uygulama becerisidir. Öz yeterlilik; yenilikçi, öncü, sorgulayıcı, kuşkucu ve gelenekçi olarak sinıflandırılmaktadır. Yiyecek-içecek işletmelerinde öz yeterliliğ̈in dışarıya yansıyan hallerinden birisi de yenilikçilik ve yenilikçiliğin eyleme dönüşmüş halidir.Bu çalışmada, Ankara, Bodrum ve Mersin illerindeki 4 ve 5 yıldızl otel işletmelerinin mutfak departmanında çalş̧anlarda bireysel yenilikçilik ve öz yeterlilik arasındaki ilişki araştırılmıştır.
\end{abstract}

Anahtar Kelimeler: Bireysel yenilikçilik, Öz yeterlilik, Otel işletmeleri, Mutfak çalışanları.

\footnotetext{
${ }^{1}$ Bu çalışma 17-19 Eylül 2019 tarihinde Bişkek/Kırgızistan'da düzenlenen III. International Congress On Cultural Heritage and Tourism/Events Kongresi'nde bildiri olarak sunulmuştur.
} 


\title{
The Relationship Between Individual Innovation Classification and Self-Efficiency: A Research in Kitchen Employees
}

\begin{abstract}
Satisfaction of hedonic emotions from food and beverage businesses has become more important than products in the focus of customers who have achieved personal satisfaction. Therefore, not only products but also innovative ideas and practices have gained great importance in ensuring customer satisfaction in food and beverage establishments. It is inevitable for enterprises that want to gain competitive advantage to develop innovative strategies.In order to innovate, it is necessary to have the ability to innovate individually. Because employees who have the ability to innovate are brave, entrepreneurial and independent people who have more original ideas than non-innovators. It is a fact that the innovative personality can provide benefits to the company in various subjects such as the supply of new products, the utilization of new production techniques, the acquisition of new customers and markets, the existence of new service methods. Self-efficacy is the form of innovative personality in the employee. Selfsufficiency: is aware of the knowledge and abilities of the employee to perform the behaviors expected from him in the related field and the ability to apply them. Self-sufficiency; innovative, pioneering, questioning, skeptical and traditionalist. One of the externally reflected states of self-efficacy in food and beverage establishments is innovation and the transformation of innovation into action.

In this study, the relationship between individual innovation and self-efficacy was investigated in the kitchen department of 4- and 5- star hotels in Ankara, Bodrum and Mersin.
\end{abstract}

Keywords: Individual innovation, Self-efficacy, Hotel managements, Kitchen employees. 


\section{Giriş}

Küresel ve yerel işletmecilikte başarılı bir işletme olmanın çeşitli etkenleri bulunmaktadır. Bu süreçte işletmeler; uluslararası ve ulusal rakipleriyle, teknolojiyle, insan ilişkileriyle, sistemlerle karşılıklı ilişkiler ve etkileşimler içerisinde olmaktadırlar. Küyerel (küresel düşünme yerel hareket etme) ekonomik sistem işletmeleri ulusal ve uluslararası büyük rekabete mecbur kılmaktadır. Bu sistemin ana kaynağı bilgiden yararlanan ekonomik büyüme ve gelişmedir. Bu sistem içerisinde başarılı olmak isteyen işletmelerin rekabet gücünün gelişmesinde yenilikçilik ve öz yeterliliğe sahip çalışanlar önemli bir yer tutmaktadır.

Yenilik, işletmelerin rekabet edebilirliği açısından sahip olması gereken önemli bir güçtür. Bu nedenle farklı disiplin dallarında yenilik tanımları yapılmıştır. Rogers (1995) yeniliği “birey ya da örgüt tarafından yeni kabul edilen fikir, uygulama veya nesne" olarak tanımlamaktadır.

Yenilikçilik konusunda bilimsel anlamda yapılan ilk çalışmalar Schumpeter (1934) tarafından yapılmıştır. Schumpeter yapmış olduğu çalışmada yenilikçiliği yeni olarak tanımlanan fikir, uygulama veya nesne, yeni bir problem çözme yöntemi özelinde "yeni birleşimler oluşturulması ve uygulanması için yeni ürün, süreç, hizmet ile ilgili yenilikler gerçekleştirmek" olarak tanımlamıştır (Işık ve Türkmendağ, 2016).

Beklenmeyen durumlar, beklenti ile sonuç arasındaki uyumsuzluk, süreç gereklilikleri, demografik gelişmeler, yeni bilgi ve ürünlere duyulan ihtiyaçlar ile bireylerin kendini ifade ve başarma ihtiyacı gibi bireysel ve örgütsel faktörler birey ve örgütü yenilikçiliğe yöneltmektedir (Acaray, 2007).

Yenilik yapmak bilgi ve tekniğe sahip olmanın yanında bireysel cesarete sahip olmayı gerektirir. Cesaretin kaynağı ise bireyin öz yeterliliğe sahip olması demektir. Drucker (1985) yeniliğin tanımını girişimcilerin farklı ürün veya hizmeti ortaya koymak için sahip olunan bilgi, öğrenme ve uygulama yeteneği olarak (Işık ve Keskin, 2013) ifade ederken, tanımın içerisinde öz yeterliliği de ifade etmektedir. Bu tanıma bakıldığında yeniliğin sadece bilgi, öğrenme ve uygulama becerisiyle sınırlı olmadığı, yenilikçi kişilerin gerekli öz yeterliliğe de sahip olması gerekli olduğu görülmektedir.

Günümüzde rekabetçilik, turizm sektöründe faaliyet gösteren işletmeleri de yenilikçi olmaya yöneltmektedir. Konukların ihtiyaç ve beklentilerinin 
karşılanması zorunluluğu otel işletmelerini proaktif ve reaktif yenilikçilik uygulamalarını rakiplerinden önce uygulamaya koymaya zorlamaktadır. Tüketicilerin dinamik yapısı ile turizmin dinamik yapısı birlikte otel işletmelerinde yenilikçi olmayı zorunlu hale getirmektedir. Bu yenilikçilik ise iş görenlerin bireysel yenilikçi olmasını gerektirmektedir. Bireysel yenilikçilik ile iş görenlerden yeni fikirler, yeni ürünler ve yeni hizmetler ortaya çkarılabilmektedir. Bireysel yenilikçilik beklenen iş görenlerin ise yeterli özgüvene sahip olmalarının sonucudur.

Dinamik bir sektör olan turizm sektöründe otel işletmelerinin başarılı olmaları ve sürekli yaşamları için yenilikçilik anlayışı oldukça önemlidir. Yenilikçilik, rekabet avantajının sağlanması, işletmenin gelecekteki bağımsızlığının korunması, pazar payı oluşturulması ve kârlılığının sürdürülebilmesinin önemli unsurlarından birisidir (Demirel ve İskân, 2003).

Günümüzde yenilikçilik iş yaşamı için bir zorunluluk haline gelmiştir. Yoğun ve acımasız rekabet örgütleri ve bireyleri iş yaşamında yenilikçi olmaya zorlamaktadır. Yenilikçi olmayan ve geleceği yaşamayan işletmelerin iş dünyasında yaşamını sürdürme şansı kalmamış gibidir. İş yaşamında yenilik, hem yeni ve farklı fikirler üretmeyi hem de gelişmeyi engelleyici problemleri çözmede önemli bir araçtır (Morris, Kuratko ve Covin, 2011). Yüksek kültürel birikim, cesaret, sabır, kararlılık, geleceği görebilmek vb. özelliklere sahip bireyler yenilikçi özellikleri taşımaktadırlar (Çavuş ve Akgemci, 2008).

Yenilik ürün ve süreç ilişkisi (OECD, 2006), hizmet, pazarlama ve örgütsel (Elçi, 2006), teknolojik ve teknolojik olmayan (Uzkurt, 2008), sürekli ve radikal (Elçi, 2006; Uzkurt, 2008), bireysel ve örgütsel olmak üzere çeşitli şekillerde bilim insanlarınca incelenmiştir. Bilim insanları yenilikçiliği algılanma şekli bakımından, yenilikçiliğin benimsenmesi açısından (öncelik, sonralık) da inceleme konusu yapmışlardır. Bu araştırmalarda yenilikçilik ve insan davranışları ilişkisi de araştırılmıştır (Kılıçer ve Odabaşı, 2010). Nieves ve Quintana (2016) otel endüstrisinde, bazı insan kaynakları yönetimi uygulamalarının yenilikçiliği etkilediği bununda insan sermayesi üzerindeki etkileri olduğunu belirlemişlerdir. Bununla birlikte, işe alım ve seçme insan kaynakları yönetimi uygulamaları, yenilikçilik performanslarını belirleseler de, çalışılan işletmelerin insan sermayesi seviyesini arttırmadığını belirlemişlerdir.

Yenilikçiliğin bir diğer gereksinimi farklı olabilmektir. İş yaşamında farklı olabilen ve bu farklılığı hedef kitleye benimsetebilen örgütler varlıklarını sür- 
dürebilmektedirler. Bu farklılık, ürün farklılığı, hizmet farklılığı, süreç farkl1lığ 1 vb. şekillerde gerçekleşebilmektedir. Bu farklılık hedef kitlelerin ilgisini çekecek nitelikte olmalıdır. Bu farklılığı anlamlı hale getirecek olan ise örgütte çalışan bireyler ve onların toplamı olan örgüttür. Bu anlamda işletmeler, toplam farklılığ oluşturabilmek ve iş ve süreçlere katma değer sağlayabilmek için bireylere yenilikler geliştirebilme fırsatını sağlaması gereklidir.

\section{Kavramsal Çerçeve}

\section{Bireysel Yenilikçilik}

Sosyal yaşamın ve iş yaşamının gelişmesinde bireyler önemli bir rol oynamaktadır. İş yaşamının koşulları, toplumsal koşullar, teknolojik koşullar ve bireysel koşullar bireyleri yenilikçi olmaya sevk etmektedir. Bireyleri iş yaşamında başarılı olmaya zorlayan iki tür yenilik vardır. Bunlar sahip olunan bilgi ve becerileri güncelleme zorunluluğu diğeri ise yeni bilgi ve teknoloji geliştirme zorunluluğudur. Her iki zorunlulukta değişik oranlarda bireyleri yenilikçi olmaya zorlamaktadır. Bu anlamda bireysel yenilikçilik "herhangi bir ürünün, hizmetin veya sürecin birey tarafından yeni olarak algılanması ve tanımlanması olarak ifade edilebilir" (Işık, 2016). Bu açıdan bakıldığında bireysel yenilikçilik, bir algı, tanımlama ve bu tanımlamanın yeni olarak kabulü olarak görülmektedir. Bireysel yenilikçilik öğrenme, kabul ve uygulama yeteneği olarak görülebilir. Aynı zamanda bireysel yenilikçilik risk alma, uyum sağlama, kabullenme, tolerans gösterme ve açlk olma gibi durumları da ifade etmektedir (Korucu ve Olpak, 2015).

Bireyler, yaratılış, aile ortamı, yetiştiği çevre, kişilik yapısı, eğitim durumu, cinsiyet, vb. iç ve diş çevre faktörlerinin etkisiyle yenilikçilik konusunda birbirlerinden farklılaşmaktadırlar. Bireysel ve toplumsal niteliklerin etkisiyle bireyler herhangi bir yeniliği, diğerlerine göre daha erken veya daha geç benimsemektedir. Bireyler aynı zamanda yenilikler konusunda değişime daha az veya daha çok istekli olabilmektedir. Bu nedenlerle bilim insanları yenilikçilik konusunda bireyleri beş kategoride sınıflandırmaktadır. Bilim insanları yenilikçi bireyleri toplumdaki dağılım düzeylerine göre; yenilikçiler $(\% 2,5)$, öncüler (\%13,5), sorgulayıcılar (\%34), kuşkucular (\%34) ve gelenekçiler (\%16) olarak sınıflandırmaktadırlar (Rogers, 1995).

Bu veriler ışığında toplumsal anlamda yenilikçiliğe bakıldığında; yenilikçiliğin ilk başlarda küçük bir kesim tarafından kabul edildiği görülmektedir. 
Toplumun büyük bir kesiminin yenilikçiliğe kuşkucu bir yaklaşım tutumu geliştirdiği ve onu sorguladıktan sonra olumlu bir bakış açısı geliştirdiği görülmektedir. Yine toplumun küçük bir kesiminin ise yenilikçiliğe direniş gösterdiği bilim insanları tarafından belirtilmektedir (Rogers, 1995; Kılıçer ve Odabaşı, 2010). Bu açıdan gelenekçi yenilikçiler, yenilik toplumun diğer bireyleri tarafından benimsendikten sonra devreye girerek yeniliği en son benimseyenleri ifade etmektedir.

Bilim insanları iş yaşamında bilimsel yenilikçiliğe yönelik araştırmalar yapmışlardır. Scott ve Bruce (1994) iş yaşamında bireysel yenilikçilik davranışının belirleyicilerini, Lu vd. (2005) teknolojik yeniliklerin kabul düzeylerini ve kabul durumlarını, Hsu, Lu ve Hsu(2007) mobil yenilik uygulamalarının yararları, kullanılabilirliği, uyumluluğunu, Jong (2007) ise yenilikçi iş davranışları ile yenilikçi örgütsel iklim etkileşimini araştırmışlardır. Yuan ve Woodman (2010) çalışma ortamında yenilikçi davranışlar ile çalışan uyumunu, Oyedoyin, Ilori, Oyebisi, Oluwale ve Jegede (2014) ise bireylerin (paydaşların) Ar\&Ge ve yenilikçilik süreçlerine katılımını araştırmışlardır. Hoarau ile Kline (2014) ise yenilikçi yaklaşımlarda bilgi paylaşımının önemi üzerin çalışmalar yapmışlardır.

Bireysel yenilikçilik konusu turizm akademisyenleri tarafından turizm işletmelerinde incelenmiştir. Atçı, Kale ve Şeker (2017) Mersin Kızalesi'nde faaliyette bulunan belediye belgeli otel işletmelerinde çift yönlülük ve bireysel yenilikçilik ilişkisini belirlemeye yönelik araştırmalarında; küçük otel işletmeleri açısından karar verici konumundaki sahip/yöneticinin bireysel yenilikçilik düzeyi ve otel işletmesinin çift yönlülüğü arasında pozitif ilişki belirlemişlerdir. Işık, Işık ve Tirak (2016), konaklama işletmelerinde duygusal emek ve bireysel yenilikçilik arasındaki ilişkiyi araştırmışlardır. Çalışma sonucunda, duygusal emek ile bireysel yenilikçiliğin alt boyutları arasında negatif yönlü bir ilişki tespit etmişlerdir. Yine Işık ve Meriç (2015) Van ilinde faaliyet gösteren 4 ve 5 yıldızlı otel yöneticilerinin yenilik düzeyleri ve kategorilerini belirlemeye yönelik çalışma yapmışlardır. Çalışma sonucunda otel yöneticilerinin orta düzey yenilikçi olduklarını ve yöneticilerinin çoğunun (\%50 den fazlası) sorgulayıcı, öncü, kuşkucu, yenilikçi ve gelenekçi yenilikçi bireyler olduklarını belirlemişlerdir. Chen (2011), Tayvan otellerinde hizmetlerde yenilik konulu çalışmasında çevresel faktörlerin yenilikte bireysel güçlere ağır bastığını ortaya koymuş̧tur. Hu, Horng ve Sun (2009), otel işletmelerinde bilgi paylaşımı ve yenilikçi hizmetlerin performans üzerindeki etkisini 
belirlemeye yönelik çalışmalarında bilgi paylaşımı, takım kültürü ve hizmet yenilikçiliği arasındaki ilişkilerin performans için önemli ve güçlü olduğunu belirlemişlerdir.

\section{Öz Yeterlilik}

Öz yeterlilik, bireylerin sahip oldukları bilgi ve becerileri etkin bir şekilde kullanabilmeleri için ilgili alanda kendi yeterliliklerine güven duymalarını ifade eder (Özerkan, 2007). Öz yeterlilik bireylerin sahip oldukları bilgi ve yetenekler ile bunları kullanabileceğine olan inancın fiiliyata geçirilmesidir. Luszczynska, Scholz ve Schwarzer (2005) öz yeterliliği, zor ve belirsiz görevleri yapabilme ve özel yeteneklere ihtiyaç duyan zorluklarla başa çıabilme konusunda kişinin öz yeteneklerine olan inancı olarak görmektedirler. Başka bir tanıma göre öz yeterlilik, kişinin belirli görevleri ve davranışları yapabileceğine olan inançtır (Salas ve Cannon-Bowers, 2001).

Genel anlamıyla öz yeterlilik, bireylerin karşılaşabileceği zorlukları aşmada sahip olduğu bilgi ve yeteneklerden yararlanabilme yeteneği olarak görülebilir. Örgütsel anlamda ise öz yeterlilik, bireylerin iş ve örgütle ilgili çözülmesi gereken her türlü problemi, sahip olduğu bilgi ve yetenekleri kullanarak çözebileceğine olan inançtır. Bu nedenle örgütsel anlamda öz yeterlilik, bireylerin iş performansını etkilediği gibi örgütsel süreçleri de doğrudan etkileyen önemli bir faktördür (Çetin, 2011). Bu açıdan öz yeterlilik, bireylerin yenilikçilik sürecinde göstermeleri gereken performans için açılayıcı bir faktördür.

Akgündüz (2013), konaklama işletmelerinde iş doyumu ile yaşam doyumu ve öz yeterlilik arasındaki ilişkiye yönelik araştırmasında, iş doyumu ile yaşam doyumu ve öz yeterlilik arasında anlamlı ve pozitif bir ilişki belirlemiştir. Öz yeterlilik, iş doyumu ile iş yaşamı arasında kısmi aracılık göstermektedir. Jaiswal ve Dhar (2015), dönüşümcü liderlik, yenilik iklimi, öz yeterlilik ve işgücü yaratıcıllğı isimli çalışmasında dönüşümcü liderliğin, çalışan yaratıcılığı için yenilikçilik ortamını geliştirebileceğini belirlemişlerdir. Ayrıca, yenilikçilik iklimi ile çalışan öz yeterliliği arasındaki ilişkide, yaratıc1öz-yeterliği yüksek çalışanların, destekleyici bir yenilik ortamı elde ettikleri zaman yaratıcı davranışlara başvurduğunu belirlemişlerdir. Şahin ve Gürbüz (2012) Bosna-Hersek Avrupa Barış Gücünde görev yapan farklı kültürlere sa- 
hip kişiler üzerinde yaptıkları araştırmada kültürel zekâ ile öz yeterliliğin görev performansı ve örgütsel vatandaşlık davranışını olumlu yönde etkilediğini belirlemişlerdir. Meydan (2011) çeşitli kamu kuruluşlarında çalışan alt ve orta kademe yöneticiler üzerinde, Özler, Giderler ve Baran (2017) öğrenciler üzerinde yaptıkları araştırmada öz yeterlilik ile iç girişimcilik arasında yüksek derecede pozitif bir ilişki belirlemiştir. Basım, Korkmazyürek ve Tokat (2008) ise çalışmalarında, çalışanların öz yeterlilik algılarının ortalamanın üzerinde, yenilikçilik davranışlarının ise yüksek düzeyde olduğunu belirlemişlerdir. Ayrıca, çalışanların öz yeterlilik algısı ile yenilikçilik arasında anlamlı bir ilişki belirlemişlerdir. Şeşen (2010), çalışmasında öz yeterlilik ile bireylerin örgütsel vatandaşlık davranışı arasında anlamlı bir ilişki belirlemiştir.

Evers, Brouwers ve Tomic (2002) Hollanda'da öğrenciler üzerinde yaptıkları çalışmada bireylerin öz yeterlilik inançlarının tükenmişliğin duyarsızlaşma ve duygusal tükenme boyutları arasında anlamlı ve negatif bir ilişki belirlemişlerdir. Kişisel başarı boyutuyla anlamlı ve pozitif bir ilişki belirlemişlerdir. Beeftink, Van Eerde, Rutte ve Bertrand (2012) ise çalışmalarında yenilikçi bilişsel tarz ile tasarımcı öz yeterlilik arasında doğrudan ve dolaylı bir ilişki belirlemişlerdir. Öz düzenleme ile öz yeterliliğin başarılı bir tasarımcı ve iş insanı olmada doğrudan etkilediğini belirtmektedirler. Hu ve Zhao (2016), çalışmalarında bilgi paylaşımının ve yaratıcı öz yeterliliğin çalışanların yenilik algısı ile pozitif ilişki içerisinde olduğunu belirlemişlerdir. Öz yeterliliğin, bilgi paylaşımı ile yenilikçilik etkilerine aracılık ettiğini ortaya koymuşlardır. Slåtten (2014) ise çalışmasında işle ilgili faktörlerin öz yeterlilik için en etkili belirleyici faktörler olduğunu ortaya koymuştur. Ayrıca, öz yeterliliğin yenilikçi faaliyetler üzerinde olumlu etkiye sahip olduğunu belirlemiştir.

\section{Yöntem}

Mutfak çalışanlarının öz yeterlilikleri ile bireysel yenilikçilik düzeylerini araştırmak amacıyla yapılan bu çalışmada, nicel araştırma yöntemlerinden anket tekniği kullanılmıştır. Araştırma Ankara, Bodrum ve Mersin illerindeki 4 ve 5 yıldızlı otel işletmelerinin mutfak departmanında gerçekleştirilmiştir. Çalışmada 450 adet soru formu kolayda örneklem olarak seçilen restoranların mutfak çalışanlarına dağıtılmış ve 300 adet geri dönüşs sağlanmıştır. Geri dö- 
nüş sağlanan soru formlarının tamamı veri analizine uygundur. Soru formunda yer alan ölçekler 5'li Likert tipinde sorulmuş olup, 1-Kesinlikle Katılmiyorum ve 5-Tamamen katıliyorum şeklindedir. Örneklemin demografik özelliklerini belirlemeye yönelik cinsiyet, yaş, medeni durum, eğitim durumu, gelir durumu, çalışılan bölüm, çalışılan pozisyon, sektörde çalışma süresi ve yenilikçilik durumu incelenmiştir.

Araştırmada bireysel yenilikçiliği belirlemeye yönelik Hurt, Joseph ve Cook (1977) tarafından geliştirilen ve 20 ifadeden oluşan ölçek kullanılmıştır. Ölçeğin 12 maddesi pozitif maddeler, 8 maddesi ise negatif maddelerdir. Pozitif maddelerden alınan puandan negatif maddelerden alınana puanın çıkarılması ve sonuca 42 eklenerek yapılan hesaplamaya göre 14 ile 94 arasında bir puan alınmaktadır. Ölçekten alınan puana göre 80 puan üstü "yenilikçi", 69-80 puan arası “öncü", 57-68 puan arası "sorgulayıcı", 46-56 puan aras1 "kuşkucu" ve 46 puan altı "gelenekçi” olmak üzere beş farklı grup yer almaktadır. Yine araştırmada kullanılan öz yeterlilik Schwarzer ve Jerusalem (1995) tarafından geliştirilen tek boyutlu 10 ifadeden oluşan ölçek ile ölçülmüştür.

Elde edilen verilere öncelikle güvenilirlik analizi yapılmış ardından katılımcıların ifadelere vermiş oldukları yanıtların ortalamaları ve standart sapmaları hesaplanmıştır. Verilerin güvenilir olduğu belirlendikten sonra öz yeterlilik ölçeği açımlayıcı faktör analizi ölçülerek geçerliliği test edilmiştir. Bireysel yenilikçilik ve öz yeterlilik arasındaki ilişkinin tespit edilmesine yönelik korelasyon ve ilişkinin nedenselliğinin ortaya konulması amacıyla regresyon analizleri gerçekleştirilmiştir. Ayrıca katılımcıların bireysel yenilikçilik sınıfına göre öz yeterlilik düzeyine göre herhangi bir farklılık olup olmadığ ve eğer varsa bu farkın hangi gruplar arasında olduğunu belirlemeye yönelik varyans analizi yapılmıştır.

\section{Bulgular}

\section{Güvenilirlik Analizleri}

Güvenilirlik analizinde güvenilirlik katsayısı 0 ve 1 arasında değer almakta ve bu değer 1'e yaklaştıkça güvenilirlik artmaktadır (Ural ve Kılıç, 2006: 286). Çalışmada kullanılan anket formunda yer alan 30 ifadeden oluşan ölçeğin güvenilirliği (Cronbach Alpha 0,911) tablo 1'de görülmektedir. 
Bireysel Yenilikçilik Sınıflandırması ve Öz Yeterlilik İlişkisi: Mutfak Çalışanlarında Bir Araştırma

Tablo 1. Güvenilirlik Analizi

\begin{tabular}{llll}
\hline Ölçek & $\begin{array}{l}\text { Cronbach's } \\
\text { Alpha }\end{array}$ & $\begin{array}{l}\text { İfadelere Göre Standartlaştırılmış } \\
\text { Cronbach's Alpha }\end{array}$ & $\begin{array}{c}\text { İfade } \\
\text { Sayısı }\end{array}$ \\
\hline Tüm Ölçek & 0,845 & 0,851 & 30 \\
\hline Bireysel Yenilikçilik & 0,807 & 0,810 & 20 \\
\hline Öz Yeterlilik & 0,835 & 0,837 & 10 \\
\hline
\end{tabular}

Katılımcıların sorulara verdikleri yanıtlara ilişkin ifade ortalamaları ve standart sapmalar tablo 2 ‘de görülmektedir.

\section{Tablo 2. Iffade Ortalamaları}

\begin{tabular}{|c|c|c|c|c|c|}
\hline & & İFADELER & SAYI & ORT. & S.S. \\
\hline \multirow{20}{*}{ 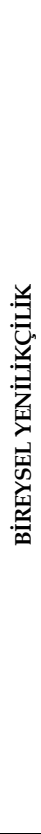 } & 1 & Yenilikleri takip ettiğim için arkadaşlarım sık sık benden bilgi ve öneri alırlar. & 300 & 3,63 & 1,060 \\
\hline & 2 & Yeni şeyleri denemekten hoşlanırım. & 300 & 3,85 & 0,958 \\
\hline & 3 & Bir şey yaparken, yeni yollar olup olmadığını araştırırım. & 300 & 3,88 & 0,951 \\
\hline & 4 & Yeni fikirleri kabul etme konusunda genellikle dikkatli davranırım. & 300 & 3,70 & 1,132 \\
\hline & 5 & Problemleri çözmek için genellikle yeni yöntemler bulurum. & 300 & 3,69 & 1,029 \\
\hline & 6 & Yeni bakş̧ açları ve yeni buluşlara şüphe ile bakarım. & 300 & 3,31 & 1,206 \\
\hline & 7 & Çevremdeki insanların kabul ettiğini görene kadar yeni fikirleri benimsemem. & 300 & 3,45 & 1,168 \\
\hline & 8 & Yenilikçilik konusunda insanlan kolay etkileyen bir kişi olduğumu düşünürüm. & 300 & 3,70 & 1,016 \\
\hline & 9 & Düşünce ve davranışlarımın yaratıc ve özgün olduğunu düşünürüm. & 300 & 3,72 & 1,049 \\
\hline & 10 & Çevremdeki insanların arasında yeniliği kabul eden en son kişi olduğumu düşünürüm. & 300 & 3,45 & 1,283 \\
\hline & 11 & Yaratıc bir kişi olduğumu düşünüyorum. & 300 & 3,67 & 1,057 \\
\hline & 12 & Yenilikler konusunda gruba liderlik etmekten hoşlanırım. & 300 & 3,76 & 1,110 \\
\hline & 13 & Çevremdeki insanların işine yaradığını görünceye kadar yenilikleri kabul etmede isteksiz davranırım. & 300 & 3,44 & 1,182 \\
\hline & 14 & Düşünce ve davranışlarımla çevremdekileri özgün olmaya teşvik ettiğimi düşünürüm. & 300 & 3,63 & 1,060 \\
\hline & 15 & Eski yaşam tarzının ve işleri eski yöntemlerle yapmanın en iyi yol olduğunu düşünürüm. & 300 & 3,49 & 1,220 \\
\hline & 16 & Problemlere ve belirsizliklere karşı mücadele ederim. & 300 & 3,78 & 1,053 \\
\hline & 17 & Yenilikleri dikkate almadan önce diğer insanların o yeniliği kullandığını görmek isterim. & 300 & 3,82 & 0,983 \\
\hline & 18 & Yeni fikirlere açık biriyim. & 300 & 3,93 & 0,974 \\
\hline & 19 & Cevaplanmamış sorular beni çözüm bulmaya yöneltir. & 300 & 3,85 & 0,928 \\
\hline & 20 & Yeni fikirlere karşı şüpheci davranırım. & 300 & 3,44 & 1,202 \\
\hline \multirow{10}{*}{ 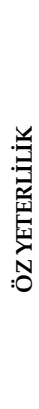 } & 1 & Yeni bir sorunla karşılaştı̆̆ımda ne yapmam gerektiğini bilirim. & 300 & 3,44 & 1,154 \\
\hline & 2 & Beklenmedik durumlarda nasıl davranmam gerektiğini her zaman bilirim. & 300 & 3,65 & 1,060 \\
\hline & 3 & Her durumda kendimi kabul ettirecek çare ve yolları bulurum. & 300 & 3,75 & 0,975 \\
\hline & 4 & Ne olursa olsun üstesinden gelirim. & 300 & 3,84 & 0,973 \\
\hline & 5 & Zor sorunların çözümünü eğer gayret edersem her zaman başarırım. & 300 & 3,49 & 1,225 \\
\hline & 6 & Projelerimi gerçekleştirmek ve hedeflerime ulaşmak bana güç gelmez. & 300 & 3,67 & 1,064 \\
\hline & 7 & Bir sorunla karşlaştı̆ım zaman onu çözebilmeye yönelik birçok fikrim var. & 300 & 3,68 & 1,065 \\
\hline & 8 & Zorlukları soğukkanlılıkla karşılarım, çünkü yeteneklerime her zaman güvenebilirim. & 300 & 3,52 & 1,135 \\
\hline & 9 & Aniden ortaya çıan sorunların üstesinden geleceğime inanıyorum. & 300 & 3,78 & 0,953 \\
\hline & 10 & Her sorun için bir çözümüm var. & 300 & 3,52 & 1,239 \\
\hline
\end{tabular}


Tablo 2'de yer alan ifade ortalamalarına bakıldığında bireysel yenilikçilik ölçeğinde yer alan "yeni fikirlere açık biriyim (ort. 3,93)" ifadesi en yüksek değere ve "problemleri çözmek için genellikle yeni yöntemler bulurum (ort.3,31)" ifadesi en düşük değere sahiptir. Öz yeterlilik ölçeğinde ise "ne olursa olsun üstesinden gelirim (ort.3,84)" en yükse değere, "yeni bir sorunla karşılaştı̆̆ımda ne yapmam gerektiğini bilirim (ort. 3,44)" ifadesi en düşük değere sahiptir.

\section{Demografik bulgular}

Demografik özelliklerden yaş, cinsiyet, medeni durum, eğitim durumu, gelir durumu, çalışılan bölüm, çalışılan pozisyon, sektörde çalışma süresi ve yenilikçilik durumu incelenmiştir.

Tablo 3. Frekans Dağılımları

\begin{tabular}{|c|c|c|c|c|c|c|c|c|c|}
\hline & Değer & Frekans & Yüzde & Kümülatif Yüzde & & Değer & Frekans & Yüzde & Kümülatif Yüzde \\
\hline \multirow{5}{*}{ 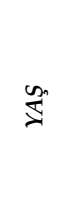 } & 18-25 Yaş & 53 & 17,7 & 17,7 & \multirow{5}{*}{ 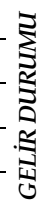 } & \multicolumn{2}{|c|}{1000 TL.- 2000 TL. 104} & 34,7 & 34,7 \\
\hline & 26-33 Yaş & 103 & 34,3 & 52 & & \multicolumn{2}{|c|}{2001 TL.- 3000 TL. 98} & 32,7 & 67,3 \\
\hline & 34-41 Yaş & 109 & 36,3 & 88,3 & & \multicolumn{2}{|c|}{3001 TL.- 4000 TL. 66} & 22 & 89,3 \\
\hline & 42 Yaş ve Üzeri & 35 & 11,7 & 100 & & 4001 TL. ve Üzeri & 32 & 10,7 & 100 \\
\hline & Toplam & 300 & 100 & & & Toplam & 300 & 100 & \\
\hline \multirow{3}{*}{ 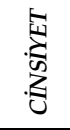 } & Kadın & 122 & 40,7 & 40,7 & \multirow{3}{*}{ 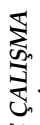 } & 1 Yildan Az & 14 & 4,7 & 4,7 \\
\hline & Erkek & 178 & 59,3 & 100 & & $1-5 Y_{11}$ & 77 & 25,7 & 30,3 \\
\hline & Toplam & 300 & 100 & & & 6-10 Yil & 108 & 36 & 66,3 \\
\hline \multirow{3}{*}{ 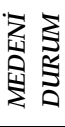 } & Bekar & 103 & 34,3 & 34,3 & \multirow{3}{*}{ : } & :11-15 Yil & 60 & 20 & 86,3 \\
\hline & Evli & 197 & 65,7 & 100 & & 16 Yıl ve Üzeri & 41 & 13,7 & 100 \\
\hline & Toplam & 300 & 100 & & & Toplam & 300 & 100 & \\
\hline \multirow{5}{*}{ 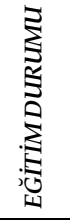 } & IlkÖÖgretim & 19 & 6,3 & 6,3 & \multirow{5}{*}{ 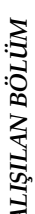 } & Ekmekçi & 7 & 2,3 & 2,3 \\
\hline & Lise ve Dengi & 71 & 23,7 & 30 & & Pastaci & 10 & 3,3 & 5,7 \\
\hline & Ön Lisans & 91 & 30,3 & 60,3 & & Restoran & 63 & 21 & 26,7 \\
\hline & Lisans ve Lisansüstü & 119 & 39,7 & 100 & & Banket & 91 & 30,3 & 57 \\
\hline & Toplam & 300 & 100 & & & Otel - Komi & 129 & 43 & 100 \\
\hline \multirow{7}{*}{ 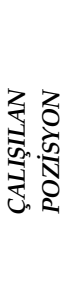 } & Stajyer & 71 & 23,7 & 23,7 & u & Toplam & 300 & 100 & \\
\hline & Komi & 116 & 38,7 & 62,3 & \multirow{6}{*}{ 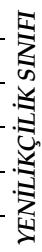 } & Gelenekçi & 11 & 3,7 & 3,7 \\
\hline & Dömi şef & 49 & 16,3 & 78,7 & & Kuşkucu & 109 & 36,3 & 40 \\
\hline & Bölüm şefi & 27 & 9 & 87,7 & & Sorgulayıcı & 149 & 49,7 & 89,7 \\
\hline & Aşçı başı yardımcısı & 16 & 5,3 & 93 & & Öncü & 21 & 7 & 96,7 \\
\hline & Aşçıbaşı & 28 & 7 & 100 & & Yenilikçi & 10 & 3,3 & 100 \\
\hline & Toplam & 300 & 100 & & & Toplam & 300 & 100 & \\
\hline
\end{tabular}


Yaşa göre frekans dağılımları incelendiğinde 26-33 yaşları $(\% 34,3)$ ve 3441 yaşları $(\% 36,3)$ olmak üzere diğer yaş gruplarına oranla daha yüksek olduğu görülmektedir. Bu durum son dönemde artan aşçlık ve pastacılık gibi mutfağın önemli dallarına olan yüksek ilgi ile açıklanabilir. Ülkemizde ve dünyada giderek yaygınlaşan aşçllık okulları gerek kısa süreli eğitim programları gerekse 2 ve 4 yıllık gastronomi eğitimi veren üniversiteler ile oldukça rağbet gören bir eğitim vermektedirler. Bu eğitimlerin son 10 senede yaygınlaştı̆̆ı düşünülecek olursa sektörde eğitimli mutfak personeline olan talebin arttığını, bununla birlikte eğitimi olmayan ve mesleğe çıraklıktan başlayan ya da aşçllık lisesi okuyarak mesleğinin başında olan grubun (18-25 yaş) azınlıkta kaldığı $(\% 17,7)$ açıklanabilir. 42 yaş ve üzeri grubun ise gelişmeye başlayan mutfak sanatları mesleğinin gelişen ve değişen yapısıyla birlikte fiziksel şartlarına uyum sağlamakta güçlük çektiği için azaldı̆̆ biçiminde yorumlanabilir.

Cinsiyet yönünden oluşan frekans değerleri aslen erkek egemen bir meslek olarak bilinen tüm mutfak sanatlarının gelişen teknoloji ve öğrenme biçimlerinin değişmesiyle birlikte kadınlar tarafından da profesyonel anlamda tercih edildiğinin bir işareti olarak açıklanabilir.

Çalışmanın örneklem grubu 4 ve 5 yıldızlı otellerde çalıştığı ve bu otellerin çalışma sistemleri oldukça düzenli olduğundan medeni durumu evli olanların, bekar olanlara oranla daha fazla olduğu görülmektedir. Otel işletmelerinde vardiyaların restoran işletmelerine göre çok düzenli olması, çalışanların düzenli bir hayat sürmelerini kolaylaştırmaktadır. Bu durumun otel işletmelerinde evli olan aşçı sayısını arttırdığı söylenebilir.

Eğitim durumu verileri incelendiğinde yaş verisi ile benzer sonuçların çıtığı görülmektedir. Mesleğe erken yaşlarda başlamış aş̧̧ıların genellikle ilkokul mezunu oldukları bilinmektedir (\%6,3). Lise ve dengi okullarda okuyanlar genellikle aşçllk meslek liselerinde okuyan ve belirli dönemlerde staj amacıyla mutfaklarda bulunan genç aşçı adaylarıdır (\%23,7). Ülkemizde gelişen aşçllık okulları ön lisans $(\% 30,3)$, lisans ve yüksek lisans $(\% 39,7)$ gibi derecelerle eğitim vermektedirler. Bulgulara göre sektörde okullu aşçı sayısının oldukça arttığı söylenebilir.

Ankete katılanların büyük bir bölümü 1000-2000 TL arasında bir gelire sahiptir (\%34,7). Bu grup stajyer ve yeni komiliğe başlayanları grubu olarak adlandırılabilir. 2001-3000 TL arasındaki (\%32,7) ve 3001-4000 TL arası gruplar 
ise komilikten orta kademe aşçllı̆g doğru uzanan kazanç değerleri olarak sayılabilir. 4001 TL ve üzeri ise otelin aşçıbaşına verilen maaşlar olarak belirtilebilir.

Ankete katılan mutfak personelinin mesleğin öğrenme ve bilgilerini pekiştirme noktasında stajyer $(\% 23,7)$ ve komi olarak çalıştıkları $(\% 38,7)$ saptanmıştır. Bununla birlikte Dömi şef (\%16,3) ve bölüm şefi (\%9) pozisyonlarında çalışanların orta kademe amirliğe süreçlerinde oldukları görülmektedir. Çalışanların Aş̧̧ıaşı yardımcısı $(\% 5,3)$ ve Aşçıbaşı $(\% 7)$ gibi üst yönetici pozisyonlarında görev aldıkları belirlenmiştir.

Aşçllık mesleğinin giriş pozisyonları olan stajyer ve komilik (\%43) mesleğin öğrenme aşamasında çalışanların yeteneklerine göre farklı departmanlarda değerlendirildikleri ve becerilerine uygun olarak en verimli departmana uyumlarını sağlamada verimlilik esasının gözetildiği sıcak mutfak veya soğuk mutfak gibi farklı bölümlerde çalışanlardan oluşmaktadır. Bu noktadan sonra çalışanlar kendi becerilerine göre banket mutfağına $(\% 30,3)$, A la Carte servis veren otel bünyesindeki restoranların mutfaklarına (\%21), pastahane ve ekmek bölümüne $(\% 5,7)$ gönderilerek sinıflara ayrılırlar.

Aşçllık mesleğinin emek yoğun yapısından dolayı sektörde belirli bir pozisyona gelebilmek ve o pozisyonun gerektirdiği tüm becerilere sahip olabilmek uzun bir zaman gerektirmektedir. Söz konusu becerilerin 1-5 yıl arasında çalışanlarda (\%25,7) öğrenme aşamasında olduğu, 6-10 yıl arası çalışanlarda (\%36) uygulama ve geliştirme aşamasında olduğu ile 11-15 yıl arasında (\%20) ve 16 yıl ve üzeri çalışanlarda (\%13,7) ise alttan gelenleri yetiştirmek üzere bilgi ve becerilerini öğretme aşamasında olduğu söylenebilir.

Çalışmanın bireysel yenilikçilik sınıfı ile ilgili frekans dağılımları mutfak personelinin yenilikçilik bulguları mesleğin doğasına uygun olarak, Gelenekçi $(\% 3,7)$, Kuşkucu $(\% 36,7)$, Sorgulayıcı $(\% 49,7)$, Öncü (\%7) ve Yenilikçi $(\% 3,3)$ olarak ortaya çıkmıstır.

\section{Öz Yeterlilik Ölçeği Açımlayııı Faktör Analizi (SPSS)}

Öz yeterlilik ölçeğinin geçerliliğini test etmek amacıyla açımlayıcı faktör analizi yapılmıştır. Açımlayıcı faktör analizi öncesi verilerin faktör analizine uygun olup olmadığın belirlemek için KMO ve Bartlett testi yapılmış ve uygun olduğu sonucuna ulaşılmıştır (KMO Bartlett 0,856 / anl. 0,000). 
Tablo 4. Öz Yeterlilik Ölçeği Açımlayıcı Faktör Matrisi

\begin{tabular}{lc}
\hline IFADELER & $\begin{array}{l}\text { FAKTÖR } \\
\text { YÜKÜ }\end{array}$ \\
\hline Yeni bir sorunla karşılaştığımda ne yapmam gerektiğini bilirim. &, 591 \\
\hline Beklenmedik durumlarda nasıl davranmam gerektiğini her zaman bilirim. &, 597 \\
\hline Her durumda kendimi kabul ettirecek çare ve yolları bulurum. &, 646 \\
\hline Ne olursa olsun üstesinden gelirim. &, 582 \\
\hline Zor sorunların çözümünü eğer gayret edersem her zaman başarırım. &, 692 \\
\hline Projelerimi gerçekleştirmek ve hedeflerime ulaşmak bana güç gelmez. &, 405 \\
\hline Bir sorunla karşlaştığım zaman onu çözebilmeye yönelik birçok fikrim var. &, 423 \\
\hline Zorlukları soğukkanlılıkla karşlarım, çünkü yeteneklerime her zaman güvenebilirim. &, 720 \\
\hline Aniden ortaya çıkan sorunların üstesinden geleceğime inaniyorum. &, 623 \\
\hline Her sorun için bir çözümüm var. &, 542 \\
\hline
\end{tabular}

Açımlayıcı faktör analizi sonuçlarına göre tüm ifadelerin faktör yükleri 0,40 ve üzerinde çıkması nedeniyle ölçeğin güvenilir olduğuna karar verilmiştir.

\section{Korelasyon Analizleri}

Öz yeterlilik ve bireysel yenilikçilik arasındaki ilişkiyi düzeyi ve yönünü belirlemeye yönelik yapılan korelasyon analizi sonuçları tablo 5'te görülmektedir.

Tablo 5. Öz Yeterlilik ve Bireysel Yenilikçilik Arası Korelasyon Matrisi

\begin{tabular}{lll}
\hline & & Bireysel Yenilikçilik \\
\hline \multirow{3}{*}{ Öz Yeterlilik } & Pearson Correlation &, $368^{* *}$ \\
\cline { 2 - 3 } & Sig. (2-tailed) &, 000 \\
\cline { 2 - 3 } & $\mathrm{n}$ & 300 \\
\hline \multirow{*}{**}{ 0,01 anlamlllk düzeyinde (2-tailed). } & \\
\hline
\end{tabular}

Korelasyon tablosunda görüldügü üzere, öz yeterlilik ile bireysel yenilikçilik arasında 0,37 düzeyinde pozitif yönlü bir ilişki tespit edilmiştir.

\section{Regresyon Analizleri}

Korelasyon analizi değişkenler arası ilişkinin düzeyini ve yönünü belirleyen ve nedenselliği açıklamakta sınırlı kalan bir analiz yöntemidir. Bu nedenle değişkenler arasındaki nedenselliği belirleyebilmek için basit doğrusal regresyon analizi yapılmıştır. 
Yapılan regresyon analizleri sonucu öz yeterliliğin bireysel yenilikçilik üzerindeki etkisini gösteren veriler Tablo 6 'da özetlenmiştir. Bu tabloya göre kurulan $\mathrm{Y}=\mathrm{b} 0+(\mathrm{b} 1)$ (Genel Tatmin) regresyon denkleminin istatistiksel olarak anlamlı olduğu $(\mathrm{p}=0,000<0,01)$ yüzde bir yanılma payı ile söylenebilir.

Tablo 6. Öz Yeterliliğin Bireysel Yenilikçilik Üzerindeki Etkisi

\begin{tabular}{llllllll}
\hline Model & $\mathbf{R}$ & $\mathbf{R}^{2}$ & Düzeltilmiş $\mathbf{R}^{2}$ & $\mathbf{F}$ & Önem & Beta & $\mathbf{T}$ \\
\hline 1 &, 368 &, 135 &, 132 & 46,658 &, 000 &, 368 & 6,831 \\
\hline
\end{tabular}

Bağımlı Değişken: Bireysel Yenilikçilik Bağımsız Değişken: Öz Yeterlilik

Modele ait $\mathrm{R} \% 0,368$, düzeltilmiş $\mathrm{R}^{2}$ ise $\% 0,135$ 'tir. Böylece öz yeterlilik, bireysel yenilikçilikteki değişkenliğin yaklaşı \%14'ünü açıklayabilmektedir.

\section{Farklılık Analizleri}

Katılımcıların bulundukları bireysel yenilikçilik sınıfına göre Varyans analizi sonuçları aşağıdaki tabloda görülmektedir.

Tablo 7: Bireysel Yenilikçilik Sınıfına Göre Varyans Analizi

\begin{tabular}{lllllll}
\hline ANOVA & \multicolumn{7}{l}{ Kareler } \\
\hline \multirow{3}{*}{ Öz Yeterlilik } & Goplamı & $\begin{array}{l}\text { Ser. Der. } \\
(\mathbf{d f})\end{array}$ & $\begin{array}{l}\text { Ortalama } \\
\text { Kare }\end{array}$ & F & Anlamlılık \\
\cline { 2 - 7 } & Grup içi & 21,568 & 4 & 5,392 & 13,170 & 0,000 \\
\cline { 2 - 7 } & Toplam & 120,782 & 295 & 0,409 & & \\
\hline
\end{tabular}

Katılımcıların bulundukları bireysel yenilikçilik sınıfına göre Anova analizi sonucu öz yeterlilik düzeylerinde anlamlı bir farklılık tespit edilmiştir ( $\mathrm{p} \leq$ $0,01)$.

Tablo 8. Varyanslarn Homojenliği

\begin{tabular}{lllll}
\hline & Levene Testi & df1 & df2 & Anlamllık \\
\hline Öz Yeterlilik & 4,459 & 4 & 295 & 0,002 \\
\hline
\end{tabular}

Varyansların homojenliği ölçmek için Levene testi sonuçlarının homojen çıkması nedeniyle Tamhane testi yapılmıştır. Katılımcıların bulundukları bireysel yenilikçilik sınıfına göre ikili karşılaştırma yapabilmek ve farklılıkları yorumlayabilmek için Tamhane testi sonuçları tablo 9'da görülmektedir. 
Tablo 9. Bireysel Yenilikçilik Sınıfına Göre Tamhane Testi Sonuçları

\begin{tabular}{|c|c|c|c|c|c|}
\hline $\begin{array}{l}\text { Bağımlı } \\
\text { Değişken }\end{array}$ & $\begin{array}{l}\text { Bireysel Yenilikçilik } \\
\text { Sınıfı (I) }\end{array}$ & $\begin{array}{l}\text { Bireysel Yenilik- } \\
\text { çilik Sınıfı (J) }\end{array}$ & $\begin{array}{l}\text { Ortalama Farkı } \\
\text { (I-J) }\end{array}$ & Std. Hata & Anlamlılık \\
\hline \multirow{5}{*}{$\begin{array}{l}\text { ÖZ } \\
\text { YETERLİL̇K }\end{array}$} & \multirow{2}{*}{ Öncü } & Kuşkucu &, $84954^{*}$ & 0,13986 & 0,000 \\
\hline & & Sorgulayıcı & ,64161 & 0,13379 & 0,001 \\
\hline & \multirow{3}{*}{ Yenilikçi } & Gelenekçi & $1,25455^{*}$ & 0,36505 & 0,045 \\
\hline & & Kuşkucu &, $94954^{*}$ & 0,13997 & 0,000 \\
\hline & & Sorgulayıcı & ,74161* & 0,13391 & 0,001 \\
\hline
\end{tabular}

Tablo 10' da anlamlı farklılık çıkan $(\mathrm{p} \leq 0,05)$ bireysel yenilikçilik gruplarına ait ifade ortalamaları ve standart sapmalar görülmektedir.

Tablo 10. Bireysel Yenilikçilik Gruplarnna Göre Değişimler

\begin{tabular}{llllll}
\hline BOYUT & GRUP & $\mathbf{n}$ & Ort. & Std. Sapma & Std. Hata \\
\hline & Gelenekçi & 11 & 3,1455 & 1,13786 & 0,34308 \\
\cline { 2 - 6 } & Kuşkucu & 109 & 3,4505 & 0,66327 & 0,06353 \\
\cline { 2 - 6 } ÖZ YETERLILİK & Sorgulayıcı & 149 & 3,6584 & 0,59504 & 0,04875 \\
\cline { 2 - 6 } & Öncü & 21 & 4,3000 & 0,57096 & 0,12459 \\
\cline { 2 - 6 } & Yenilikçi & 10 & 4,4000 & 0,39441 & 0,12472 \\
\cline { 2 - 6 } & Toplam & 300 & 3,6337 & 0,68999 & 0,03984 \\
\hline
\end{tabular}

Tablo 9'da yer alan Tamhane testi sonuçlarına ve tablo 10'da yer alan gruplara ait ortalamalara bakıldığında, bireysel yenilikçilik gruplarından yenilikçi (ort. 4,40) ile sorgulayıcı (ort. 3,66) arasında (anl. 0,001), kuşkucu (ort. 3,45 ) arasında (anl. 0,000), gelenekçi (ort. 3,15) arasında (anl.0,045) anlamlı bir farklılık tespit edilmiştir. Bireysel yenilikçilik gruplarından öncü (ort. 4,30) ile sorgulayıcı $(3,66)$ arasında (anl. 0,001$)$ ve kuşkucu (ort. 3,45) arasında (anl. $0,000)$ anlamlı bir farklılık tespit edilmiştir.

\section{Sonuç}

Öz yeterlilik, bireylerin sahip oldukları bilgi ve becerileri etkin bir şekilde kullanabilmeleri için ilgili alanda kendi yeterliliklerine güven duymaların ifade eder. Araştırmada mutfak çalışanlarının öz yeterliliği bireysel yenilikçiliklerinin değişkenliğini düşük seviyede etkilediği ulaşılan sonuçlardan bir tanesidir. Farklı çalışmalarda daha yüksek etki oranlarına ulaşılmış olsa da aşçılık mesleğinin doğası ve emek yoğun yapısı gereği bireylerin sahip oldukları bilgi ve becerileri konusunda kendilerine güven duymaları uzun bir süreç 
gerektirmektedir. Mutfakta yapılan tüm işlerin farklı bölümlere ayrılması ve herkesin kendi bölümünde uzmanlaşması da bu süreci uzatan bir faktördür. Bu durum bireyleri iş yaşamında başarılı olmaya zorlayan sahip olunan bilgi ve becerileri güncelleme zorunluluğu ile yeni bilgi ve teknoloji geliştirme gibi yenilik türlerinin eş zamanlı olarak uygulanmasını oldukça güçleştirmektedir. Çalışmanın bir diğer önemli sonucu ise mutfak çalışanlarının yenilikçi düzeylerinin araştırma ölçeğinin geliştirildiği çalışmanın (Rodgers, 1995) sonuçlarına benzer bulgulara rastlanmış olmasıdır. Çalışmada yenilikçi mutfak çalışanları toplumdaki dağılım düzeylerine göre; yenilikçiler $(\% 3,3)$, öncü yenilikçiler (\%7), sorgulayıcı yenilikçiler (\%49), kuşkucu yenilikçiler $(\% 36,3)$ ve gelenekçiler (\%3) olarak ortaya çıkmıştır. Mutfak çalışanları öğrenme süreçlerinin geçirdikleri stajyerlik ve komilik pozisyonlarında mesleğin gerektirdiği temel bilgi ve becerileri kazanırlar. Bu dönemde çalıştıkları operasyonun gerektirdiği tüm farklı işlerde zaman harcayarak, kendi yeteneklerine uygun bir departmanı belirlemeye çalışırlar. Bu süreçte geleneksel reçetelerin ve geleneksel mutfak kültürünün benimsenmesi mesleğin doğasında bulunan bir gerekliliktir. Aş̧̧ıların bu süreçten sonra kendi yeteneklerini keşfetmeleri noktasında yaptıkları her işe kuşkucu bir tutum ile yaklaşmaları da sıklıkla görülen bir tutumdur. Zira yaptıklarının doğruluğunda ve işin tam yapılmasından kaynaklanan kuşkuları bulunmaktadır. Orta kademe bölüm şefi olmaya başlayan teknik ve metotları etkin kullanan bir aşçı geçtiği bu yeni aşamada yenilikçi davranışlarını sorgulamaya ve diğer aşçların hangi işleri nasıl yaptıklarına dair araştırmalar ve gözlemler yapmaya başlar. Sorgulayıcı yenilikçilik iş geliştirme ve yeni ürünlerin geliştirilmesinde sıklıkla görülmektedir. Yenilikçi fikirlerin genellikle orta kademede bulunan aşçlık yetenek ve becerileri gelişmiş ancak sanatsal ve bilimsel bilgileri eksik olan aşçılardan çıkması ve sonrasında öncü ve yenilikçi olarak sayılabilecek aşçıbaşılar tarafından uygulanmasının asıl sebebi de sorgulayıcı yenilikçi görüş olarak belirtilebilir. Öncü ve yenilikçi aş̧̧lar üst kademeye daha fazla yaklaşan, artık büyük operasyonlarda farklı özellikteki misafir kitlelerine uygun ürünler geliştiren aşçılardır. Bu aşamaya gelmek için uzun yıllar çalışmanın yanısıra, gözlem yapmak, gezmek ve diğerlerinin neler yaptığını araştırmak gerekli olduğundan sektördeki öncü ve yenilikçi aşçıların sayısı diğerlerine oranla daha az olmaktadır.

Turizm sektöründe ülkeler arası, destinasyonlar arası ve işletmeler arası çok yoğun bir rekabet yaşanması nedeniyle, turizm sektörünün önemli bir 
parçası olan yiyecek içecek işletmelerinin ana merkezi durumunda olan mutfak ve mutfak personellerinin bireysel yenilikçilik düzeylerinin artırılması gerektiği çalışmanın bulgularından anlaşılmaktadır. Diğer bir ifadeyle, işletmelerin ve dolayısıyla ülkenin turizm sektöründe rekabet gücünün artırılması için çalışanların bireysel yenilikçilik düzeylerinin yüksek olması gerekmektedir.

Bu çalışma yönetim ve örgütsel davranış konularında öz yeterliliğin bireysel yenilikçiliğe olan etkisini ve bireysel yenilikçilik sınıflandırmasının aşçlardaki düzeyini ölçmek amacıyla yapılmıştır. Çalışmanın sonucundaki bulguların gelecekte bu alanda çalışma yapmak isteyen araştırmacılara ışık tutacağı düşünülmektedir. Bireysel yenilikçiliğin Türk mutfağının ve aşçl1ğının gelişmesinde en önemli etkenlerden biri olduğu düşünüldüğünde ileride yapılacak çalışmaların nitel analiz yöntemleri kullanılarak konuyu açılamaya çalışmaları, farklı kişilik özelliklerinin bireysel yenilikçilikle ilişkilerini araştırmaları ve bireysel yenilikçiliği geliştirmeye yönelik eğitim ve öğretim faaliyetleri geliştirmeleri bu araştırmadan çıkan öneriler olarak sıralanabilir. Ayrıca turizm sektörü içerisinde yer alan farklı işletmelerin (konaklama tesisi, seyehat acentası gibi) çalışanlarının da bireysel yenilikçilik düzeylerinin belirlenmesi araştırmacılara önerilmektedir. 


\title{
EXTENDED ABSTRACT
}

\section{The Relationship Between Individual Innovation Classification and Self-Efficiency: A Research in Kitchen Employees}

\author{
Ediz Güripek - Cemal İnce - Serdar Eren \\ Tokat Gaziosmanpasa University, Kutahya Dumlupinar University
}

Today, factors such as competitiveness, the dynamic nature of consumers, and the dynamic nature of tourism make it necessary to be innovative in hotel businesses. Innovation is a crucial element of providing a competitive advantage, preserving the enterprise's future independence, creating the market share, and sustaining its profitability (Demirel and İskan, 2003). Such innovation requires employees to be individual innovators. New ideas, new products, and new services can be created by those who work with individual innovation. Individual innovation is the result of the employees who are expected to have sufficient self-confidence.

Individual innovativeness can be defined as "the perception and definition of any product, service or process as new by the individual" (Iş1k, 2016). From this perspective, individual innovativeness is seen as a perception, definition, and acceptance of this definition as a new concept. Individual innovation can be seen as the ability to learn, accept, and apply. At the same time, individual innovativeness also refers to situations such as risk-taking, adaptation, acceptance, tolerance, and openness (Korucu \& Olpak, 2015). Scientists consider innovative individuals according to their distribution levels in society; innovators (2.5\%), pioneer innovators (13.5\%), interrogators (34\%), skeptics (34\%) and traditionalists (16\%) (Rogers, 1995).

Self-efficacy refers to individuals' confidence in their competencies in the relevant field to effectively use their knowledge and skills (Özerkan, 2007). Self-efficacy is the actualization of individuals' knowledge and abilities and the belief that they can use them. Luszczynska, Scholz, and Schwarzer (2005) see self-efficacy as a belief in a person's self-abilities to do challenging and uncertain tasks and cope with difficulties that require special skills. According to another definition, self-efficacy believes that a person can perform 
specific tasks and behaviors (Salas \& Cannon-Bowers, 2001). Generally speaking, self-efficacy can be seen as individuals' ability to benefit from their knowledge and skills to overcome the difficulties they may encounter. In the organizational sense, self-efficacy believes that individuals can solve all kinds of problems related to work and organization by using their knowledge and skills. Therefore, organizational self-efficacy is an essential factor that affects individuals' job performance and directly affects organizational processes (Çetin, 2011). In this respect, self-efficacy is an explanatory factor for individuals' performance in the innovation process.

The questionnaire technique, one of the quantitative research methods, was used in this study, which was conducted to investigate the self-efficacy and individual innovation levels of kitchen workers. The research was carried out in the kitchen department of 4 and 5-star hotels in Ankara, Bodrum, and Mersin provinces. In the study, 450 questionnaires were distributed to the restaurants' kitchen staff selected as a sample, and 300 feedback were obtained. To determine the demographic characteristics of the sample, gender, age, marital status, educational status, income level, department of employment, position, working time in the sector, and innovativeness were examined.

In the research, a scale consisting of 20 expressions developed by Hurt, Joseph, and Cook (1977) was used to determine individual innovativeness. The self-efficacy dimension was measured by a one-dimensional scale consisting of 10 expressions developed by Schwarzer and Jerusalem (1995). First, reliability analysis was performed on the data obtained, then the means and standard deviations of the participants' responses to the statements were calculated. After the data were determined to be reliable, the self-efficacy scale was tested by measuring the exploratory factor analysis. Regression analyses were carried out to determine the correlation between individual innovativeness and self-efficacy and reveal the relationship's causality.

Self-efficacy of kitchen workers is one of the results reached in the study that affects individual innovativeness variability at a low level. Although higher impact rates have been achieved in different studies, it takes a long process for individuals to have confidence in their knowledge and skills due to the nature and labor-intensive nature of the culinary profession. Separating all the work done in the kitchen into different sections and specializing in 
their department is also a factor that prolongs this process. This situation makes it very difficult to apply simultaneously the necessity of updating the knowledge and skills that compel individuals to be successful in business life and the simultaneous application of innovation types such as new knowledge and technology development.

Another significant result of the study is that findings similar to the previous study results (Rodgers, 1995) in which the research scale of the innovative levels of kitchen workers was developed. In the study, according to the distribution level of innovative kitchen workers in the society, innovators (3.3\%), pioneering innovators (7\%), questioning innovators (49\%), skeptical innovators $(36.3 \%)$, and traditionalists $(3 \%)$. Kitchen workers gain the necessary knowledge and skills required by profession in the internship and committee positions they undergo during their learning process. During this period, they try to determine a department that suits their abilities by spending time in all the different jobs required by the operation they work. In this process, adopting traditional recipes and traditional cuisine culture is an inherent requirement of the profession. It is also a typical attitude that cooks approach everything they do with a skeptical attitude to discover their talents after this process. A chef, who has started to become a mid-level department demichef, uses techniques and methods effectively, begins to question his innovative behavior in this new stage, and makes research and observations on what jobs and how other cooks do. Inquiry innovation is a standart in business development and the development of new products. The main reason why innovative ideas emerge from chefs who have developed cooking skills and skills but lack artistic and scientific knowledge and are applied by chefs, who can be considered pioneering and innovative, can be stated as the innovative questioning view.

It is understood from the findings of the study that the individual innovation levels of the kitchen and culinary personnel, which are the main centers of the food and beverage businesses, should be increased due to the intense competition between countries, between destinations and businesses in the tourism sector. In other words, to increase the competitiveness of the enterprises and the country's tourism sector, the employees' innovation levels must be high. 


\section{Kaynakça / References}

Acaray, A. (2007). Küçük ve orta boy işletmelerde yenilik yönetimi: yenilik yönetiminde etkili olan örgütsel yapı ve faktörlere ilişkin bir araştırma. Yayımlanmamış yüksek lisans tezi. Kocaeli Üniversitesi Sosyal Bilimler Enstitüsü, Kocaeli.

Akgündüz, Y. (2013). Konaklama işletmelerinde iş doyumu, yaşam doyumu ve öz yeterlilik arasındaki ilişkinin analizi. Celal Bayar Üniversitesi Sosyal Bilimler Dergisi, 11(1), 180-204.

Atçı, D., Kale, A. ve Şeker, F. (2017). Otel işletmecilerinin bireysel yenilikçilik profili ve çift yönlülük (ambidexterity) düzeyi ilişkisi. Işletme ve İktisat Çalışmalan Dergisi, 5(3), 47-58.

Basım, H. N., Korkmazyürek, H. ve Tokat, A. O. (2008). Çalışanların öz yeterlilik algılamasının yenilikçilik ve risk alma üzerine etkisi: kamu sektöründe bir araştırma. Selçuk Üniversitesi Sosyal Bilimler Enstitüsü Dergisi, 19, 121-130.

Beeftink, F., Van Eerde, W., Rutte, C. G. ve Bertrand, J. W. M. (2012). Being successful in a creative profession: the role of innovative cognitive style, self-regulation, and self-efficacy. Journal of Business and Psychology, 27(1), 71-81.

Çavuş, M. F. ve Akgemci T. (2008). İşletmelerde personel güçlendirmenin örgütsel yaratıcılık ve yenilikçiliğe etkisi: imalat sanayiinde bir araştırma. Selçuk Üniversitesi Sosyal Bilimler Enstitüsü Dergisi, 20, 229-244.

Chen, W. J. (2011). Innovation in hotel services: culture and personality. International Journal of Hospitality Management, 30(1), 64-72.

Çetin, F. (2011). Örgüt içi girişimcilikte öz yeterlilik algısı ve kontrol odağının rolü. Business and Economics Research Journal, 2(3), 69-85.

Demirel, Y. ve İskan Z. (2014). Örgütselöğrenmenin yenilikçilik üzerineetkisi: otomotiv sektöründe bir araştırma. Bilgi Ekonomisi ve Yönetimi Dergisi, 9(2), 137-151.

Drucker, P. (1985), Discipline of innovation. Harvard Business Review, 63(3), 67-72.

Elçi, Ş. (2006). Inovasyon: kalkınmanın ve rekabetin anahtan (Genişletilmiş Yeni Baskı). Ankara: Nova Yayınları.

Evers, W. J., Brouwers, A. ve Tomic, W. (2002). Burnout and self-efficacy: a study on teachers' beliefs when implementing an innovative educational system in the Netherlands. British Journal of Educational Psychology, 72(2), 227-243.

Hoarau, H. ve Kline, C. (2014). Science and industry: sharing knowledge for innovation. Annals of Tourism Research, 46, 44-61.

Hsu, C. L., Lu, H. P. veHsu, H. H. (2007). Adoption of the mobile internet: an empirical study of multimedia message service (MMS). The International Journal of Management Science, 35, 715-726. 
Hu, M. L. M., Horng, J. S. ve Sun, Y. H. C. (2009). Hospitality teams: knowledge sharing and service innovation performance. Tourism Management, 30(1), 41-50.

$\mathrm{Hu}$, B. ve Zhao, Y. (2016). Creative self-efficacy mediates the relationship between knowledge sharing and employee innovation. Social Behavior and Personality: an international journal, 44(5), 815-826.

Hurt, H. T., Joseph, K., ve Cook, C. D. (1977). Scales for the measurement of innovativeness. Human Communication Research , 4, 58-65

Işık, C. ve Keskin, G. (2013). Bilgi ekonomilerinde rekabet üstünlüğü oluşturulması açısindan inovasyonun önemi. Atatürk Üniversitesi İktisadi ve İdari Bilimler Dergisi, 27(1), 41-57.

Işık, C. ve Türkmendağ, T. (2016). Atatürk Üniversitesi Turizm Fakültesi öğrencilerinin bireysel yenilikçilik algılarının belirlenmesi. Gazi Üniversitesi Turizm Fakültesi Dergisi, 1, 70-99.

Işık, C., Işık, Z. ve Tırak, L. (2016). Turizm amaçlı konaklama işletmelerinde duygusal emek ile bireysel yenilikçilik ilişkisi: Palandöken örneği. Uluslararası Ekonomi ve Yenilik Dergisi, 2(2), 117-133.

Işık, C. ve Meriç, S. (2015). Otel yöneticilerinin bireysel yenilikçi kapsamında değerlendirilmesi: van ili örneği. Girişimcilik ve İnovasyon Yönetimi Dergisi, 4(1), 1-16.

Jong, J. P. J. (2007). Individual innovation the connection between leadership and employees' innovative work behavior. Unpublished doctorate thesis. Amsterdam University, Amsterdam School of Economics Research Institute.

Jaiswal, N. K. ve Dhar, R. L. (2015). Transformational leadership, innovation climate, creative self-efficacy and employee creativity: a multilevel study, International Journal of Hospitality Management, 51, 30-41.

Kılıçer, K. ve Odabaşı, H. F. (2010). Bireysel yenilikçilik ölçeği (BYÖ): Türkçeye uyarlama, geçerlik ve güvenirlik çalışması. Hacettepe Üniversitesi Eğitim Fakültesi Dergisi, 38, 150-164.

Korucu, A. ve Olpak, Y. (2015). Öğretmen adaylarının bireysel yenilikçiliközelliklerinin farklı değişkenler açısından incelenmesi, Ĕ̆itim Teknolojisi Kuram ve Uygulama, 5(1), 109-127.

Michael, L. H., Hou, S. T. ve Fan, H. L. (2011). Creative self-efficacy and innovative behavior in a service setting: optimism as a moderator. The Journal of Creative Behavior, 45(4), 258-272.

Lu, J., Yao, J. E. ve Yu, C. S. (2005). Personal innovativeness, social influences and adoption of wireless internet services via mobile technology. Journal of Strategic Information Systems, 14, 245-268. 
Luszczynska, A., Scholz, U. ve Schwarzer, R. (2005). The general self-efficacy scale: multicultural validation studies. The Journal of Psychology, 139(5), 439-457.

Meydan, C. H. (2011). İş tatmini ve öz yeterliliğin örgüt içi girişimciliğge etkisi: kamu sektöründe bir araştırma. Çukurova Üniversitesi Sosyal Bilimler Enstitüsü Dergisi, 20(1), 25-40.

Morris, M. H., Kuratko D. F. ve Covin J. G., (2011). Corporate entrepreneurship and innovation. Natorp: Cengage/South-Western Publishers.

Nieves, J. ve Quintana, A. (2018). Human resource practices and innovation in the hotel industry: the mediating role of human capital. Tourism and Hospitality Research, 18(1), 72-83.

OECD (2006). Oslo kılavuzu yenilik verilerinin toplanması ve yorumlanması için ilkeler (3. Baskı). Ankara: TUBITAK.

Oyedoyin, B., Ilori, M. O., Oyebisi, T., Oluwale, B. A. ve Jegede, O. O. (2014). Involvement of stakeholders in the R\&D and innovation process: an analysis of Nigeria's innovation system. Journal of Entrepreneurship and Innovation Management, 3(1), 1-24.1

Özerkan, E. (2007). Öğretmenlerin öz-yeterlik algılarn ile öğrencilerin sosyal bilgiler benlik kavramlan arasındaki ilişki. Yayınlanmamış yüksek lisans tezi. Trakya Üniversitesi, Sosyal Bilimler Enstitüsü, Edirne.

Özler, N. D. E., Giderler, C. ve Baran, H. (2017). Öz yeterlilik ve kontrol odağının bireylerin girişimcilik niyeti üzerindeki etkisini belirlemeye yönelik bir araştırma. International Journal of Management Economics \& Business, 13, 736-747.

Rogers, E. M. (1995). Diffusion of innovations. New York: Collier Macmillan Publisher.

Schumpeter, J. A. (1934). The theory of economic development. London: Oxford University Press:

Salas, E. ve Cannon-Bowers, J. A. (2001). The science of training: a decade of progress. Annual Review of Psychology, 52, 471-499.

Schwarzer, R. ve Jerusalem, M. (1995). Generalized self-efficacy scale. J. Weinman, S. Wright, ve M. Johnston (Der.), Measures in health psychology: A user's portfolio. Causal and control beliefs içinde (s. 35-37). Windsor, UK: NFER-NELSON.

Scott, S. G. ve Bruce, R. A. (1994). Determinants of innovative behavior: a path model of individual innovation in the workplace. Academy of Management Journal, 37(3), 580-607.

Slåtten, T. (2014). Determinants and effects of employee's creative self-efficacy on innovative activities. International Journal of Quality and Service Sciences, 6(4), 326-347. 
Şahin, F. ve Gürbüz, S. (2012). Külttürel zekâ ve öz-yeterliliğin görev performansı ve örgütsel vatandaşlık davranışı üzerinde etkisi: çokuluslu örgüt üzerinde bir uygulama ISGUC The Journal of Industrial Relations and Human Resources, 14(2), $123-140$.

Şeşen, H. (2010). Kontrol odağı, genel öz yeterlik, iş tatmini ve örgütsel adalet algısının örgütsel vatandaşlık davranışna etkisi: Ankara'da bulunan kamu kurumlarunda bir araştırma. Hacettepe Üniversitesi İktisadi ve İdari Bilimler Fakültesi Dergisi, 28(2), 195-220.

Uzkurt, C. (2008). Pazarlamada değer yaratma aracı olarak yenilik yönetimi ve yenilikçi örgüt kültürü. İstanbul: Beta Basım A.Ş.

Yuan, F. ve Woodman, R. W. (2010). Innovative behavior in the workplace: the role of performance and image outcome expectations. Academy of Management Journal, 53(2), 323-342.

\section{Kaynakça Bilgisi / Citation Information}

Güripek, E., İnce, C. ve Eren, S. (2021). Bireysel yenilikçilik sınıflandırması ve öz yeterlilik ilişkisi: Mutfak çalışanlarında bir araştırma. OPUS-Uluslararası Toplum Araştırmaları Dergisi, 17(33), 278-302. DOI: 10.26466/opus.816491 